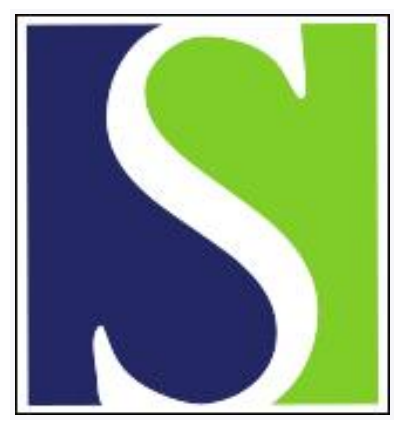

Scand J Work Environ Health 2009;35(1):7-18

https://doi.org/10.5271/sjweh.1295

Published online: 09 Dec 2008, Issue date: 00 Jan 2009

Meta-analysis of the effects of health promotion intervention in the workplace on depression and anxiety symptoms

by Martin A, Sanderson K, Cocker F

Affiliation: School of Management, Private Bag 16, Hobart, 7000, Australia. Angela.Martin@utas.edu.au

Refers to the following texts of the Journal: 1997;23(1):54-59

2006;32(6):431-442 2006;32(6):515-527 1999;25(6):589-596

The following articles refer to this text: 2010;36(6):433-434;

2014;40(3):230-234; 2014;40(6):582-596; 2019;45(4):324-332;

2019;45(6):546-559

Key terms: anxiety; anxiety symptom; depression; depression risk; depression symptom; employee; health promotion; intervention; mental health; meta-analysis; review; systematic review; workplace

This article in PubMed: www.ncbi.nlm.nih.gov/pubmed/19065280

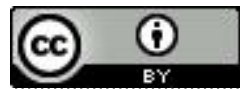




\title{
Meta-analysis of the effects of health promotion intervention in the workplace on depression and anxiety symptoms
}

\author{
by Angela Martin, PhD, ${ }^{1}$ Kristy Sanderson, PhD, ${ }^{2}$ Fiona Cocker, BA Hons ${ }^{2}$
}

\begin{abstract}
Martin A, Sanderson K, Cocker F. Meta-analysis of the effects of health promotion intervention in the workplace on depression and anxiety symptoms. Scand J Work Environ Health. 2009;35(1):7-18.
\end{abstract}

\begin{abstract}
Objectives The aim of the study was to investigate whether different types of health promotion intervention in the workplace reduce depression and anxiety symptoms.

Methods A systematic review and meta-analysis of the literature was undertaken on workplace health promotion published during the period 1997-2007. Studies were considered eligible for inclusion if they evaluated the impact of an intervention using a valid indicator or specific measure of depression or anxiety symptoms. The standardized mean difference was calculated for each of the following three types of outcome measures: depression, anxiety, and composite mental health.

Results Altogether 22 studies were found that met the inclusion criteria, with a total sample size of $3409 \mathrm{em}-$ ployees postintervention, and 17 of these studies were included in the meta-analysis, representing 20 intervention-control comparisons. The pooled results indicated small, but positive overall effects of the interventions with respect to symptoms of depression [SMD $0.28,95 \%$ confidence interval $(95 \% \mathrm{CI}) 0.12-0.44$ ] and anxiety (SMD $0.29,95 \%$ CI 0.06-0.51), but no effect on composite mental health measures (SMD 0.05, 95\% CI -0.03-0.13). The interventions that included a direct focus on mental health had a comparable effect on depression and anxiety symptoms, as did the interventions with an indirect focus on risk factors.
\end{abstract}

Conclusions When the aim is to reduce symptoms of depression and anxiety in employee populations, a broad range of health promotion interventions appear to be effective, although the effect is small.

Key terms depression risk; employee; mental health; systematic review.

Depression and anxiety are the most common forms of mental disorder. These conditions are widely reported to be increasing in prevalence, and they have the greatest lifetime risk estimates, ranging from $20 \%$ to $55 \%$, depending on the source of the estimate (18). However, these conditions are also the most manageable, as they are usually responsive to treatment, particularly if intervention takes place within the early stages of the development of the disorder (19). It is increasingly argued that the utilization of the workplace as a site for the delivery of interventions designed to prevent, screen for, or treat depression and anxiety among employee populations (20) is both logistically attractive, since the workplace provides access to a large proportion of the adult population, and a socially responsible corporate strategy (21). Moreover, recent research has linked depression to impaired work performance (22), workplace safety (23), and high levels of absenteeism and early retirement (24); therefore, there is currently considerable financial imperative for organizations to contribute to its prevention and management (25).

Consequently, strategies for mental health promotion are increasingly being implemented in workplace settings, and they constitute an important topic for applied research. The field of research on mental health promotion is beset with considerable debate and confusion around what constitutes "mental health" and "mental illness", issues that are particularly pertinent when considered in the context of the workplace $(26,27)$. Much of the debate about what mental health promotion actually is stems from philosophical differences between "pathogenic" or clinical approaches focused on the problems of individuals, and humanistic or social capital approaches, which draw attention to the systemic determinants of health (28). While this debate is contextually important in understanding the considerable variety in approaches taken in the studies reviewed in the present research, it is outside the scope of this paper to provide

1 School of Management, University of Tasmania, Hobart, Australia.

2 Menzies Research Institute, University of Tasmania, Hobart, Australia.

Correspondence to: Dr A Martin, School of Management, Private Bag 16, Hobart, 7000, Australia. [E-mail: Angela.Martin@ utas.edu.au] 
an in-depth theoretical discussion of these issues. For the purposes of this review, mental health promotion is broadly defined as encompassing a wide range of activities designed to have a positive effect on mental health, including those targeting healthy individuals (universal), at risk subgroups (selected), and high risk or symptomatic individuals (indicated) (29). Our review focused on a broad range of potential strategies that includes each of these approaches.

Given that occupational stress has been indicated as a risk factor for the development of depression and anxiety disorders (30), stress management programs are a ubiquitous strategy for mental health promotion in the workplace. Programs in organizational stress management vary widely in their objectives, structure, and target groups (31). Two recent meta-analyses showed a moderate effect for cognitive-behavioral or multimodal work-stress interventions on psychological complaints, but no effect for interventions at the organizational level $(32,33)$. Effectively managing occupational stress is undoubtedly important in promoting mental health and preventing depression and anxiety. However, given the existing evidence of the complex relationship between physical and mental health (eg, stress and coronary heart disease), a much broader, more integrated approach has been called for, including the integration of physical and mental health promotion in the workplace (34, $35)$. Research evidence showing that improvements in physical health are associated with better mental health outcomes is starting to accumulate. For example, a recent meta-analysis of 117 studies on weight loss showed its effectiveness in reducing depression (36), and physical activity interventions often demonstrate mental health benefits (37). The reverse can also occur with mental health interventions that show a positive impact on physical health (38). Although the disciplines of workplace health promotion and occupational safety and health view the workplace in different ways, an integrated approach (from psychological and public health orientations) that recognizes the need for collaboration across these disciplines is emerging (39).

As the psychological, physical, and environmental risk factors for such common mental health disorders as depression and anxiety represent such a wide range of potential intervention targets, many of which co-occur, it is important that research attention be focused not only on the effectiveness of the different types of intervention, but also on the potential for interventions to have broader than intended effects. The growing concern for public health outcomes and increased interest in cost effectiveness necessitates a closer look at how research on health promotion intervention is conducted in workplace settings (40). Reviews and meta-analyses tend to focus on evaluating interventions promoting physical or mental health promotion exclusively. Hence the objective of our study was to provide an initial overview and evaluation regarding the potential of a variety of interventions using workplace health promotion to function as strategies for mental health promotion; that is, interventions to promote mental health can either directly target depression and anxiety symptoms through psychological interventions or indirectly target them via known risk factors such as smoking (41), chronic disease (42), substance abuse (43), and obesity or inactivity (44) by using health promotion interventions. The occupational health approach emphasizes the promotion of mental health through the prevention of occupational stressors that emanate from work. Organizationally targeted interventions that aim at ameliorating an important environmental risk factor for depression and anxiety, that of a poor psychosocial work climate (45), could also be considered an indirect route for promoting the mental health of employees. Indeed, it has been recently noted that, although we know a lot about the relationship between the work environment and health, the prevention of mental ill health (eg, stress) in the workplace remains one of the main challenges of occupational health psychology (46).

Our objective was to investigate the effectiveness of both these direct and indirect approaches and summarize the range of studies on workplace health promotion that include depression and anxiety as intervention outcomes. Studies that include a mental health outcome as an intervention evaluation criterion obviously expect a reduction in symptoms, even when the study does not state that the reduction of depression or anxiety is the primary aim. We classified these interventions as indirectly focused on depression and anxiety symptoms.

\section{Methods}

\section{Search strategy}

The following search strategy was carried out using the major relevant database search engines (eg, MEDLINE, psycINFO, ProQuest, Web of Science). We divided our keyword searches into three categories, one term from each category being present in order to generate a database hit. The first group of search terms were related to the focus on the workplace (the intervention had to target working adults) by including variants or derivatives of words such as occupation or organization or employees or work. Next, the focus on mental health promotion was reflected in a long list of search terms that might indicate a primary or secondary focus on depression or anxiety, such as health or mental or psychological or well-being or depression or anxiety. Finally, search terms related to the focus on studies evaluating the effectiveness of interventions were entered. We utilized the Cochrane search terms for identifying interventions and trials, 
for example, intervention or training or program or efficacy or randomized control group. The search was also limited to articles reported during 1997-2007 (decade prior to the commencement of the study) and in English. Article titles and abstracts were screened by two of the authors to determine eligibility. In addition, a hand search of key journals and reference lists of all studies selected for inclusion in the analysis was also conducted. Appendix 1 contains a summary of the search strategy.

\section{Inclusion criteria}

The inclusion criteria dictated that the studies contained a quantitative evaluation of workplace health intervention that reported outcome on a standardized mental health screening measure for depression or anxiety. This measure could be specific to depression or anxiety symptoms $\{$ eg, the Beck Depression Inventory (BDI); the anxiety subscale of the Depression, Anxiety and Stress Scales (DASS), a composite screening measure that provides a combined assessment of depression and anxiety symptoms [eg, the General Health Questionnaire (GHQ)] or a subscale of a general health measure that has evidence of validity as a depression or anxiety screening tool [eg, the SF-12 mental health summary scale (47)\}. The intervention had to target mental health directly or indirectly through a known risk factor for depression or anxiety, such as those reviewed in the introduction (smoking, chronic disease, substance abuse, obesity or inactivity, and poor psychosocial work climate). As the study was concerned with workplace mental health promotion, the interventions reviewed were limited to those delivered in or via the participants' workplace.

\section{Data extraction}

The variables extracted covered intervention descriptors, sample characteristics, implementation characteristics, quality of the research design (use of control group, random allocation) and outcome indicators or effect sizes. As with two recent meta-analyses in this area $(32,33)$, we did not use a quality rating score in the analysis as it introduces subjectivity and is prone to incomplete data. This approach is conservative (48). Coding instructions and guidelines were developed by the first and second authors in order to reduce the subjectivity of decisions made by the primary coder (the third author). On completion of the coding, the first author independently checked the coding of each of the papers. Instances in which disagreement with the initial coding decisions occurred were resolved by consensus. All data were entered into an SPSS (version 14, SPSS Inc, Chicago, IL, USA) data file, and data required for the calculation of effect sizes were also entered into the RevMan program (The Cochrane Centre, The Cochrane Collaboration, Copenhagen, Denmark).

\section{Statistical analysis}

Our primary outcome was the scores of the depression, anxiety, or composite mental health measures used as screening tools for these conditions. To retain as much information as possible on the study outcomes, we calculated one effect size for each of the depression, anxiety, or composite measures that were used in each study. Treatment effect across the studies was then analyzed separately for each of these three outcomes, avoiding the substantial dependency among effect sizes that would otherwise arise (49). One exception was a study that used two composite measures (10), in which both effect sizes were included in the composite measures analysis. For the controlled trials, treatment effect was based on the difference in the posttreatment means between the treatment and control groups. Standardized mean differences were calculated as our effect-size measure. We calculated Hedge's $g$, which is the difference in posttreatment means divided by the pooled poststandard deviation, with adjustment for small sample bias. Data were coded such that a positive standardized mean difference indicates that the intervention group was superior to the comparison group. Two studies reported mean scores on the SF12 and SF36 measures but not the standard deviations $(12,17)$; therefore, the values were derived from published normative data (49). For studies that compared two intervention groups with the same control group, we estimated the standardized mean difference for each treatment-control comparison; thus a small number of dependent standardized mean differences from the same study was included. Although a small number of correlated standardized mean differences was unlikely to greatly affect the analysis (48), we conducted a sensitivity analysis in which we included only one treatment-control comparison from each study, selecting the most comprehensive intervention for inclusion, and examined the effect on the pooled standardized mean differences. When the standardized mean differences could not be directly calculated from the reported data, we used standard imputation methods (eg, derivation from an F statistic) (49), and these are reported separately.

As our research question was deliberately broad, we expected substantial heterogeneity in the study populations and interventions. For completeness, we present pooled results across the studies, although these results should be interpreted with caution given the diversity of studies included in this review. The standardized mean differences were pooled for the depression, anxiety, and composite measures separately. A meta-analysis was conducted using RevMan software, with pooled results expressed as the standardized mean differences (SMD) with $95 \%$ confidence intervals $(95 \% \mathrm{CI})$. The standardized mean differences were weighted by their precision 
such that the studies with larger sample sizes contributed more to the pooled estimate. Statistical heterogeneity was considered to be present if Cochran's Q statistic was significant at $\mathrm{P}<0.10$, or if the $\mathrm{I}^{2}$ statistic, which provides the percentage of variation in outcome attributable to heterogeneity between studies, was greater than $50 \%$ (50). Fixed effects models are reported unless heterogeneity is present, in which case random effects models have been reported. The pooled analysis only included comparable standardized mean differences, and thus some of these differences have been reported separately (imputed values and those calculated from pre-post scores and change scores) (51). For the outcome measures with at least 10 estimates (52), we constructed funnel plots to detect evidence of potential publication bias. To reduce subjective error in the judgment of asymmetry, we compared our plots with published examples representing low, moderate, high, or very high asymmetry (52). A subgroup analysis investigated whether the treatment effect varied for the interventions that directly targeted mental health versus those that did not (eg, physical activity interventions).

\section{Results}

\section{Overview of search results and included studies}

As the search strategy was deliberately very broad, we generated 2271 hits. Figure 1 summarizes the results of the inclusion and exclusion decisions. Only 52 articles appeared to meet the criteria for inclusion on the basis of the initial screening, as the remainder did not contain a relevant intervention. Upon more careful inspection, 20 of these articles were excluded primarily because they did not contain a specific measure of depression or anxiety symptoms. Many of these studies used stress-related outcome measures or general psychosocial functioning or well-being scales that have not been established in the literature as valid indicators of depression or anxiety symptoms. A few studies included depression indicators that were not considered valid, such as a single item or one that appeared to have been developed specifically for the study. The application of these inclusion criteria resulted in a total of 32 studies being deemed suitable for the coding and data entry. After the coding, a further 10 studies were excluded, as insufficient information was provided with which to calculate our measure of effect. This process resulted in a total of 22 studies, which we subjected to a systematic review. The effect sizes for 5 of these studies have been reported separately, as alternative methods were required to estimate the standardized mean differences, and 17 were eligible for a pooled analysis representing 20 intervention-control comparisons.

The 22 included studies represented a total sample size of 3632 (mean 157.9, SD 103.7) employees after the intervention, with a total sample size of 2640 (mean 138.9, SD 93.5) in the 17 studies included in the pooled analysis (1-17). The age range of the sample was 19-69 years. An average of 47.9 (SD 25.6)\% of the participants

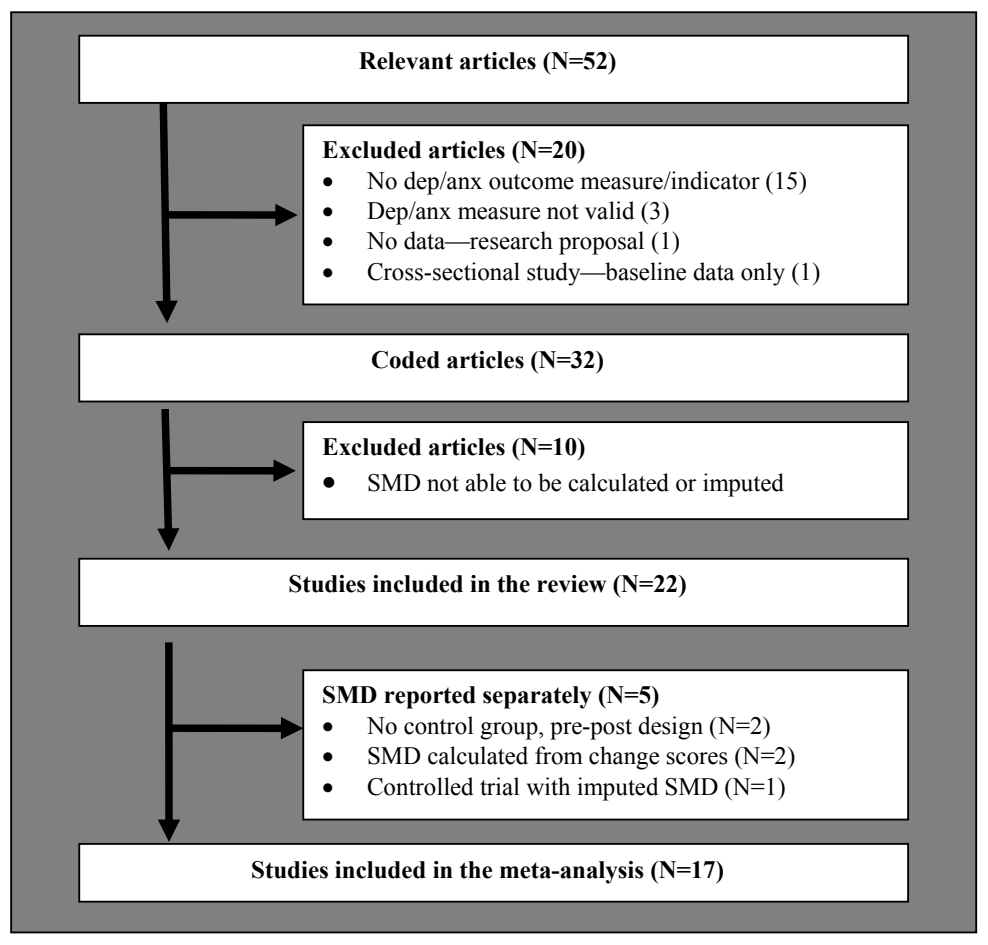

Figure 1. Flow chart of the search strategy. $($ dep $=$ depression, anx = anxiety, SMD = standardized mean difference) 
were female, calculated from the 16 studies (1-14, 16, $17)$ that reported the gender distribution. Nine studies included a follow-up $(1,3-5,9,10,12-14)$, the interval from the preintervention assessment ranging from 1 month to 3 years. At the follow-up, the total sample size was 1604 (mean 145.8, SD 119.2). Two studies $(4,10)$ included a second follow-up; these results are not presented as the number of studies was too small to be meaningful. Most of the reviewed studies were published in either medical or occupational psychology journals. The participants were most likely to be from North America or Europe and working in health, government, or community services (white- or "pinkcollar" workers).

Table 1 presents a brief summary of the intervention, relevant outcome measure or measures, and target population for each of the included studies. The studies that had a direct focus on mental health $(1,4-6,10,11$, 14) comprised approximately $53 \%$ of those reviewed and mainly utilized psychoeducation focused on cognitive behavior or training in coping skills within a stress management framework. Those without a direct focus on mental health $(2,3,7-9,12,13,15-17)$ were generally directed towards risk factors such as physical activity, poor work environment, and cardiovascular disease. Approximately $52 \%$ of the interventions were "selected" (2, 6-9, 11-13, 15), 30\% were "universal" $(3,16,17)$, and $18 \%$ were "indicated" $(1,4,5,10,14)$ in terms of their approach to mental health promotion (29). Most of the interventions were individually targeted, and only one study (5) in the meta-analysis included an exclusive focus on the organization. Of the studies included in the meta-analysis, nine $(3,5,11-17)$ measured only one type of outcome (most commonly a composite measure), and eight (1, 2, 4, 6-10) measured two types of outcome (most commonly depression and anxiety).

\section{Effects of mental health interventions using workplace health promotion}

The standardized mean differences of the individual studies and the pooled results after the intervention for the 17 studies included in the meta-analysis are shown in figure 2. For the depression and anxiety measures, the standardized mean differences for the individual studies after the test ranged from no difference between the intervention and control to a large effect size of 0.8 . The effect varied more for the composite measures, ranging from a small benefit of -0.21 in the control group to a moderate benefit of 0.71 for the intervention. The results from the fixed-effects meta-analysis models indicated small, but positive overall effects in the interventions on symptoms of depression (SMD 0.28, 95\% CI 0.12-0.44) and anxiety (SMD 0.29 , 95\% CI $0.06-0.53$ ), but no effect on composite measures (SMD 0.05, 95\% CI $-0.03-0.13)$. Statistical heterogeneity was not present in these pooled analyses, as all of the $\mathrm{Q}$ statistic P-values were $>0.10$ and the $\mathrm{I}^{2}$ was well below $50 \%$. For the three studies that compared two intervention groups with the same control group $(1,3,13)$, a sensitivity analysis that included only the standardized mean difference for the most comprehensive treatment group from each study produced similar results (depression SMD 0.31, 95\% CI 0.14-0.47; anxiety SMD 0.32, 95\% CI 0.07-0.57; composite SMD 0.06 , 95\% CI $-0.02-0.15)$. For the outcome measures with at least 10 effect estimates (depression and composite), we inspected funnel plots for evidence of potential publication bias. Both the

Table 1. Summary of studies included in the review. (DASS = Depression, Anxiety, Stress Scales, CBT = cognitive behavior therapy, BDI = Beck Depression Inventory, HADS = Hospital Anxiety Depression Scale, Zungs-SDS = Zung's Self-Rating Depression Scale, BSI = Brief Symptom Inventory, CES-D = Centre for Epidemiologic Studies Depression Scale, STAI/STPI = State-Trait Anxiety Inventory/State-Trait Personality Inventory, IPAT = Institute for Personality and Ability Testing Depression Scale, SF-12 = 12-item Short Form Survey, SF-36 = 36-item Short Form Survey, GHQ = General Health Questionnaire)

\begin{tabular}{lllll}
\hline Author & $\begin{array}{l}\text { Intervention } \\
\text { target }\end{array}$ & $\begin{array}{l}\text { Inter- } \\
\text { vention } \\
\text { type }\end{array}$ & Intervention description & $\begin{array}{l}\text { Type of } \\
\text { mental Study } \\
\text { health } \\
\text { promotion }\end{array}$ \\
& & design & $\begin{array}{l}\text { Out- } \\
\text { come } \\
\text { measure }\end{array}$ \\
\hline
\end{tabular}

Studies included in the meta-analysis

\begin{tabular}{|c|c|c|c|c|c|}
\hline $\begin{array}{l}\text { Atlantis et } \\
\text { al, } 2004\end{array}$ & $\begin{array}{l}\text { Increasing } \\
\text { physical activity }\end{array}$ & Individual & $\begin{array}{l}\text { Aerobic and weight-training exercise, plus } \\
\text { behavior modification }\end{array}$ & Selected & RCT \\
\hline $\begin{array}{l}\text { Blonk et al, } \\
2006(1)\end{array}$ & $\begin{array}{l}\text { Reduction of } \\
\text { depression and } \\
\text { anxiety symp- } \\
\text { toms (direct) }\end{array}$ & $\begin{array}{l}\text { Com- } \\
\text { bined }\end{array}$ & $\begin{array}{l}\text { Two work-related, stress management } \\
\text { interventions: (i) extensive CBT conducted } \\
\text { by a psychotherapist, (ii) brief CBT con- } \\
\text { ducted by "labor experts" }\end{array}$ & Indicated & RCT \\
\hline $\begin{array}{l}\text { Bond \& } \\
\text { Bunce, } \\
2000 \text { (3) }\end{array}$ & $\begin{array}{l}\text { Work stress re- } \\
\text { duction (indirect) }\end{array}$ & Individual & $\begin{array}{l}\text { Two work-related, stress management in- } \\
\text { terventions: (i) acceptance \& commitment } \\
\text { therapy to enhance coping, (ii) innovation } \\
\text { promotion program in which individuals } \\
\text { identify \& change causes of occupational } \\
\text { strain }\end{array}$ & Universal & RCT \\
\hline
\end{tabular}

DASS, Casino employees (identiSF-36 fied as having low physical activity)

DASS Self-employed workers (unable to work due to psychiatric complaint)

BDI, Large media organization GHQ12 (managerial, creative \& technical employees) 
Table 1. Continued.

\begin{tabular}{lllll}
\hline Author & $\begin{array}{l}\text { Intervention } \\
\text { target }\end{array}$ & $\begin{array}{l}\text { Inter- } \\
\text { vention } \\
\text { type }\end{array}$ & Intervention description & $\begin{array}{l}\text { Type of } \\
\text { mental } \\
\text { health } \\
\text { promotion }\end{array}$
\end{tabular}

Studies included in the meta-analysis continued

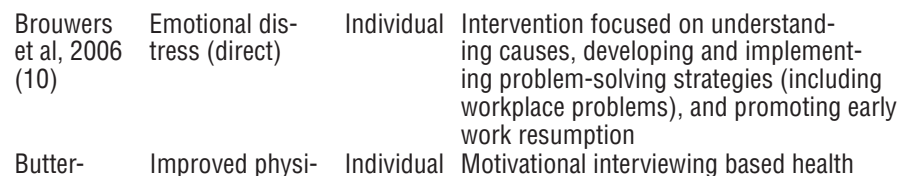

worth et al, cal \& mental

2006 (11) health (direct)

Feurstein Ergonomic risk Individual Combined ergonomic and job-stress inter-

et al, 2004 \& work stress re-

(12) duction (indirect)

Gardner et Stress reduction Individual Compared the role of modifying dysfunc- Selected RCT

(13) propriate behavioral coping strategies in stress management training

Godard et Depression or

(14) toms (direct)

Grime, Emotional dis-

2004 (4) tress (direct)

Kawakami Stress \& health

et al, 1999 risk reduction

(15) (indirect)

Kitchener Knowledge \& Com-

\& Jorm, stigma of mental bined

2004 (16) health (indirect)

Individual Organized health promotion during medical consultations with occupational physician

Individual Computerized "beating the blues" CBT program

Individual Mailed advice on reducing psychological stress, blood pressure, serum lipids \& sick leave

Program to improve mental health literacy, Universal RCT reduce stigmatizing attitudes, increase confidence to help others in the workplace \& improve participants' own mental health

McCraty Emotional health, Individual Emotion refocusing technique with physi- Selected RCT

et al, 2003 including depres- ological feedback (heart rhythms)

(6) sion (direct)

Mino et al, Stress reduction Individual Stress management program using cogni- Selected RCT

2006 (7) (indirect) tive behavior therapy

Mutrie et Indirect

al, 2002

(17)

Carlson, ior \& lifestyle

1999 (8) change (indirect)

Sheppard Stress reduction Individual

et al, 1997 (indirect)

(9)

Kawakami Focused on de- Organiza- Work environment, stress reduction proet al, 1997 pressive symp- tional gram implemented by working committee (5) toms (direct) al, 2006 (indirect) tional cognitions with teaching of ap-

al, 2006 anxiety symp-

Peters \& Health behav-
Individual Self-help intervention for increasing active Universal RCT commuting behavior

Individual Multimodal intervention including stress Selected RCT management, counseling \& health promotion

Transcendental meditation compared with Selected RCT education control of corporate stress management gram implemented by working committee
of supervisors, included survey of work stressors \& problem-solving processes

Indicated

Quasi-ex- Zung's perimental, SDS randomized groups
HADS, Various workers (on sick leave

SF-36 related to mental health)

Quasi-ex- SF-36 University employees (eligible perimental; for health benefits)

matched

SF-12 World bank employees (workrelated symptoms in the upper extremities

GHQ-12 British National Health Service workers, most from intellectual disability service (highstress occupations) Various workers (employees on sick leave in relation to anxiety or depression perimenta randomized groups HADS

British National Health Service employees (with recent stress-related absenteeism)

GHQ-12 Manufacturing (plant workers): high stress workplace

SF-12 Government employees

BSI Information technology workers (hypertensive)

GHQ- $\quad$ Manufacturing, plant workers 30, (high-stress workplace)

CES-D

SF-36 Health care workers

STAI Maintenance workers (high health risk behavior)

STAI Branch of high security, federal government agency employees (high-stress occupation)

Blue-collar workers (high depression scores)

\section{Studies reviewed but not included in the meta-analysis}

McCraty Stress and health Individual Emotion refocusing technique with physi- Selected RCT ological feedback (heart rhythms)

et al, 2003 risk reduction

(53) a (indirect)

Petterson Work environ-

Organiza- Empowerment intervention or employee

tional participation program

Universal Pre-post, no control

$(70)^{b}$

Lang et al, Smoking cessa- Individual Compared effectiveness of a worksite phy- Selected RC

$2000(41)^{\text {a }}$ tion (indirect) sician recommending giving up smoking with more active quitting strategies

Lavoie- Work environ- Organiza- Participatory organizational interven-

Tremblay ment (indirect) tional tion to improve the psychological work

et al, 2005 environment

Selected Pre-post, PS no control

\section{BSI Correctional officers} (hypertensive)

GHQ-6 Aged care nurses

CES-D Employees of an electricity and gas company (smokers)

$(56)^{b}$

Guppy \& Alcohol misuse Individual Company-based counseling program for

Marsden, (indirect) employees with alcohol-related problems
Selected Pre-post, no control
Health care workers (high stress occupation)

GHQ-12 Transportation workers (alcohol problems)

a Excluded from the analysis due to inadequate data provided with which to calculate the effect size.

${ }^{b}$ Excluded due to the lack of a control design. 


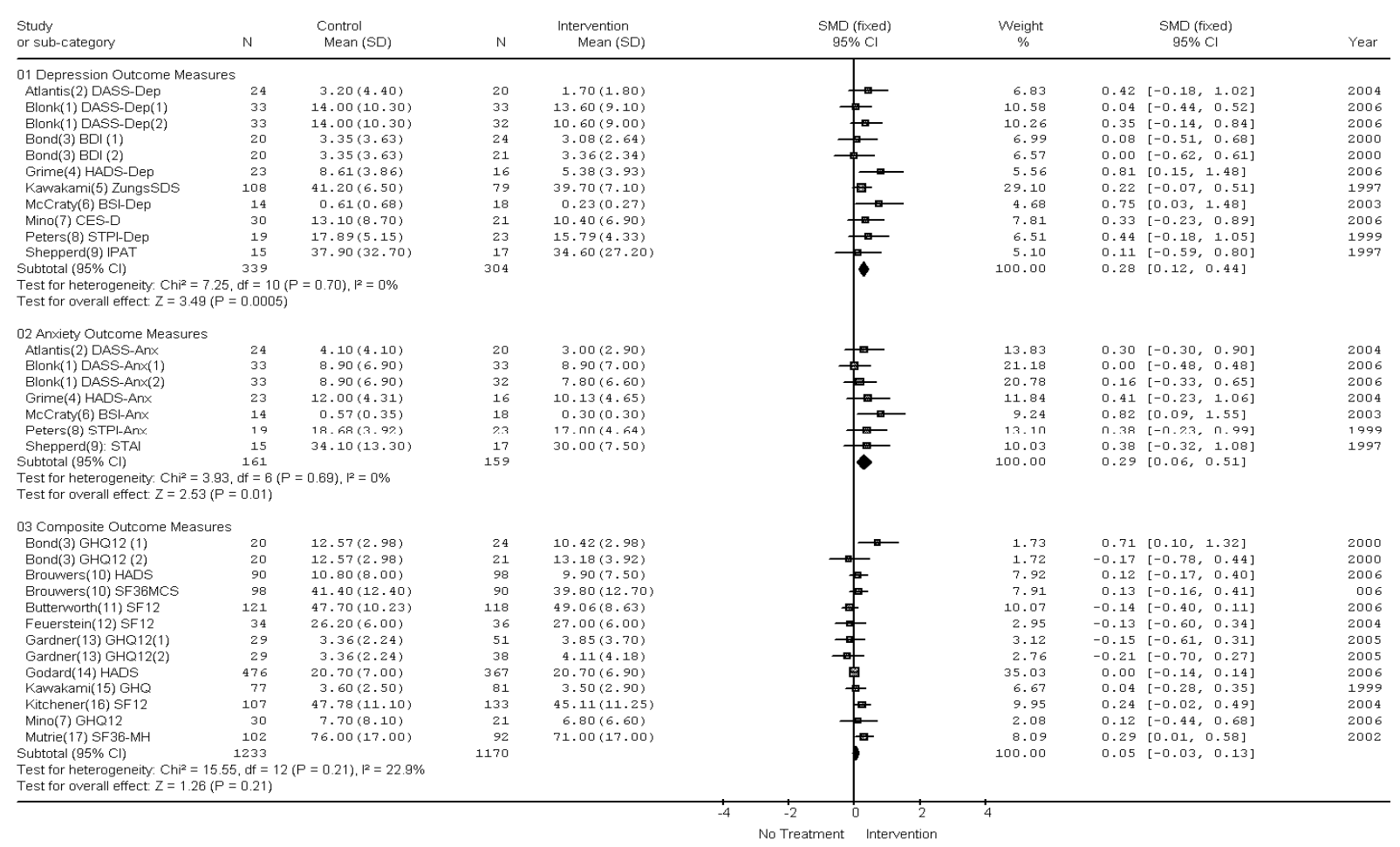

Figure 2. Overall effects of the reviewed interventions on depression, anxiety, and the composite measures.(DASS = Depression, Anxiety, Stress Scales, BDI = Beck Depression Inventory, HADS = Hospital Anxiety Depression Scale, Zungs-SDS = Zung's Self-Rating Depression Scale, BSI = Brief Symptom Inventory, CES-D = Centre for Epidemiologic Studies Depression Scale, STAI/STPI = State-Trait Anxiety Inventory/State-Trait Personality Inventory, IPAT = Institute for Personality and Ability Testing Depression Scale, SF-12 = 12-item Short Form Survey, SF-36 = 36-item Short Form Survey, GHQ = General Health Questionnaire)

depression and composite measure plots showed low-tomoderate evidence of asymmetry and hence a lower risk of publication bias. [The funnel plots can be obtained from the first author.]

In a subgroup analysis, interventions that included a direct focus on mental health $(1,3-6,10,11,14,16)$ produced similar standardized mean differences as those that had an indirect focus on risk factors $(2,7-9,12$, $13,15,17)$, with small positive effects for depression (SMD 0.31, 95\% CI 0.10-0.51, compare with 0.24, 95\% CI -0.01-0.49) and anxiety (SMD 0.25, 95\% CI 0.03-0.53, compare with SMD 0.35, 95\% CI -0.02-0.71) and no effect for composite measures (SMD 0.01, 95\% CI - $0.10-0.11$, compare with SMD $0.12,95 \%$ CI $0.01-0.25)$. Heterogeneity was minimal in the analyses for direct (depression $\mathrm{Q}=5.21, \mathrm{df}=4, \mathrm{P}=0.27, \mathrm{I}^{2}=23.2 \%$; anxiety $\mathrm{Q}=3.71, \mathrm{df}=3, \mathrm{P}=0.29, \mathrm{I}^{2}=19.1 \%$; composite $\mathrm{Q}=2.58, \mathrm{df}=3, \mathrm{P}=0.46, \mathrm{I}^{2}=0.0 \%$ ) and indirect (depression $\mathrm{Q}=1.86, \mathrm{df}=5, \mathrm{P}=0.87, \mathrm{I}^{2}=0 \%$; anxiety $\mathrm{Q}=0.04$, $\mathrm{df}=2, \mathrm{P}=0.98, \mathrm{I}^{2}=0 \%$; composite $\mathrm{Q}=11.18, \mathrm{df}=8, \mathrm{P}=0.19$, $\left.\mathrm{I}^{2}=28.5 \%\right)$ interventions.

The outcomes at follow-up are presented in figure 3 . The follow-up interval ranged from 1 month after the baseline measurements to 3 years. As heterogeneity was present, we used random effects models. Initial improvement was maintained for the depression and anxiety outcomes at the follow-up. The outcome was also improved for the composite measures. The analysis of the composite measures also had a clear outlier (SMD 1.66); with this study removed from the sensitivity analysis, the pooled result for the composite measure was similar to that of the postintervention results (SMD $0.19,95 \%$ CI $0.00-0.38$ ). Caution is needed when these follow-up results are interpreted, as only 9 of the 17 studies reported follow-up data, the follow-up intervals varied, and there was substantial heterogeneity for the anxiety and composite measures.

The standardized mean differences are reported separately for five studies due to differences in the methodology. Two controlled trials with standardized mean differences derived from change scores found a slight worsening on the of the Centre for Epidemiologic Studies Depression Scale (CES-D) scores for the intervention group in a smoking cessation trial (SMD -0.08) (41) and virtually no difference with the Brief Symptom Inventory for depression (SMD 0.03) or anxiety (SMD 0.05) (53). A controlled trial evaluating a stress management program that required an imputed effect size (derived from the F statistic) had a standardized mean difference of 0.69 on the Centre for Epidemiologic Studies Depression Scale (54). Two studies without a control group (one with counseling for employees with alcohol problems and the other with a participatory work environment program) had respective before-after 


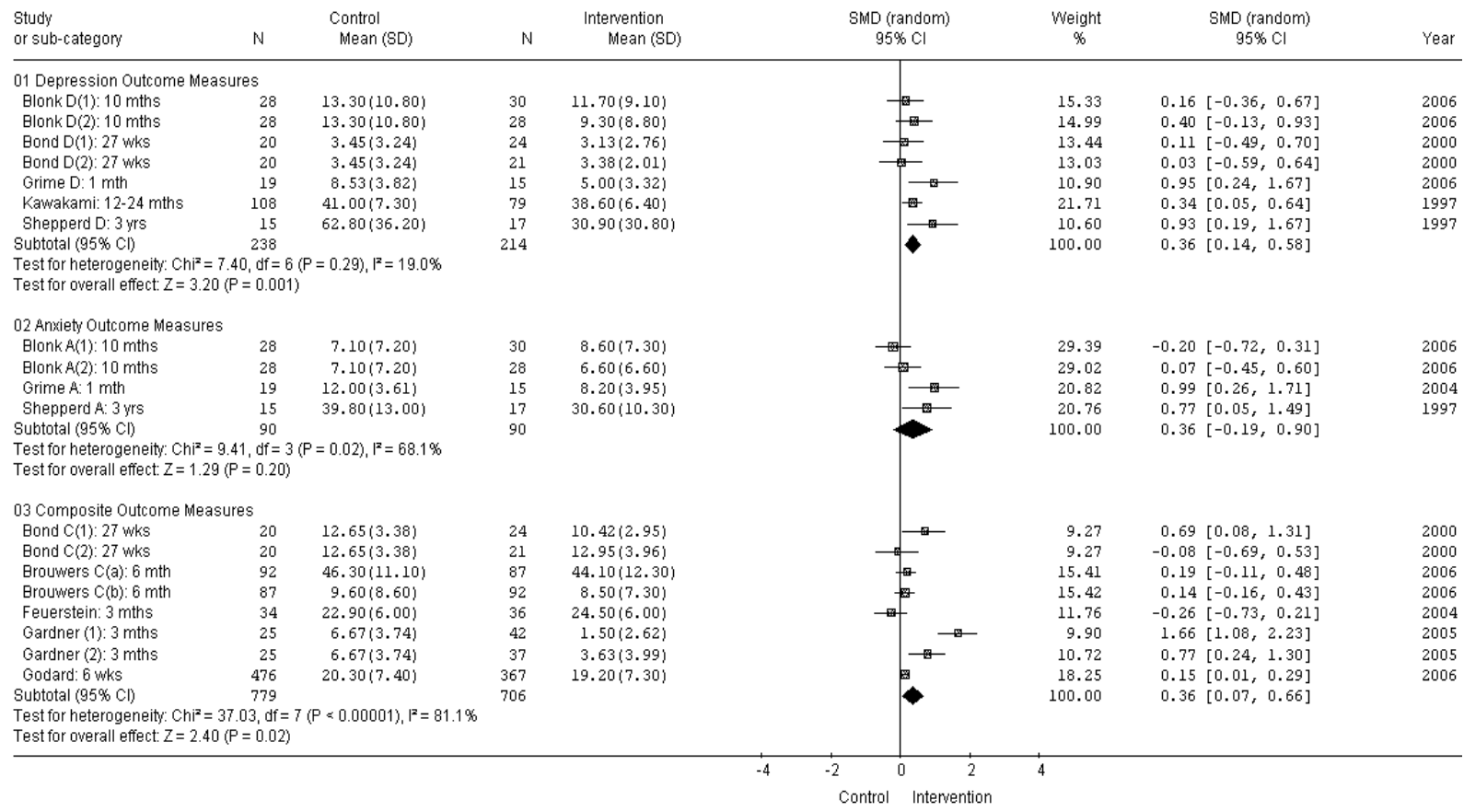

Figure 3. Follow-up effects of the reviewed interventions on depression, anxiety, and the composite measures.

standardized mean differences of 0.44 on the basis of the change in the GHQ (55), and -0.20 in the Psychiatric Symptom Inventory (derived from the percentage of change) (56).

\section{Discussion}

The results indicated small, but positive overall effects for symptoms of depression and anxiety in the interventions reviewed, but no effects for the composite outcome of the mental health measures. The interventions with a direct focus on mental health had a similar beneficial effect on symptoms as those with an indirect focus on risk factors.

The effect sizes observed were generally smaller, but in the same positive direction as those reported in similar meta-analyses $(32,33)$. Three studies showed larger-than-average effects and were clearly effective within a positive confidence interval range, even though their samples were all small. McCraty et al (6) were able to show a reduction in symptoms of both depression and anxiety, as measured with the Brief Symptom Inventory, in a stress-management program for hypertensive employees. Their program included instruction in refocusing positive emotion and restructuring techniques enhanced by feedback on heart rate variability. This is an interesting use of a psychophysiological approach in a selected population. Grime (4) reduced depression symptoms measured by the Hospital Anxiety Depression
Scale with a CBT (cognitive behavior therapy) program on emotional distress for employees with recent stress-related absenteeism. These two interventions were directed towards employee groups with a higher risk, a factor that may explain the larger effect sizes. The standardized mean differences of 0.75 and 0.81 , respectively, for the depression scores in these studies are comparable with that observed for psychological therapy among clinically depressed persons (SMD 0.82) (57). Bond \& Bunce (3) found reduced scores on the GHQ in a group that received acceptance and commitment therapy that sought to enhance people's ability to cope with work-related strain. However, in comparison, they also evaluated an innovation promotion program that helped people to identify and then innovatively change causes of occupational strain, but the result showed a negative impact on the participants.

\section{Limitations and directions for future research}

Most of the effects observed by us were empirically small. This result is consistent with the evidence on the efficacy of public health strategies in the prevention or reduction of depression symptoms, and a recent metaanalysis reported a similar average effect (SMD 0.22) (58) to that found for depression outcomes in our analysis (SMD 0.28). From a public health perspective, it is recognized that a small effect applied to a larger number of people may produce overall greater improvement in population health than a larger effect applied to a smaller, targeted group of persons (59). A wider application of 
public health interventions of modest effect to promote employee health may be a cost-effective strategy (60). It should also be noted that, given the heterogeneity in the interventions and populations, there was a range of clinical severity of symptom pretreatment, and a restriction of the range of the pretreatment means may have contributed to our results.

We also noted some methodological issues while conducting our review. As in other reviews of occupational health and safety intervention, major issues are the use of uncontrolled designs, small samples, a lack a theoretical reasoning, and the omission of important intervention details (40). Obviously our exclusion criteria regarding study design and the requirements for data presentation that enabled the meta-analysis limited the number of studies we could analyze. We also observed a theoretical positioning of most of the interventions in our review and noted that the mention of nonmethodological issues, such as the cost of implementation, was also rare. Researchers are urged to consider publishing this information in order to guide academic research on the mechanisms of intervention action and to aide public health and organizational decision making in relation to the cost-effectiveness of health promotion programs in the workplace.

As research continues on the integration of physical and mental health promotion, the detection of crossdomain effects in well-controlled studies may reveal important economies of scale that we were unable to detect in our small and simple review. Further research should specifically address our question, as well as focus on collecting evidence that could contribute to future meta-analyses of a much larger number of studies. This process would enable our findings to be confirmed and investigated in relation to a more complex model that includes predictors and moderators of effect.

For the last 20 years, stress management researchers have been talking about the need for interventions to include components at both the individual and organizational level (61). This study showed that such approaches are still rare, and only 5 of the 22 studies reviewed included a focus on the organization, either exclusively or through a combined approach. Although there is a strong ethical and pragmatic rationale for the use of interventions at the organizational level $(62,63)$, the paucity of well-controlled studies evaluating them may be influenced by a range of factors. There are many reasons why the evaluation of interventions at the organizational level is complex and difficult to achieve (46). First, there is a lack of data supporting the effectiveness of interventions at this level. Authors have argued that interventions at the organizational level have little or no effect (33), positive and negative effects (64), and mixed and less positive than person-focused interventions (65). Organizational interventions may take longer than the average 3- to 12-month follow-up period to demonstrate an impact (66). Other reviews have found that process evaluation is infrequently employed in intervention studies, and this lack may explain the variability in outcomes (67). Some researchers even deem randomized clinical trials to be an invalid form of testing when they concern interventions carried out within a complex organizational system $(68,69)$.

\section{Concluding remarks}

If the aim is to reduce depression and anxiety symptoms in employee populations, a broad range of interventions using health promotion in the workplace appears to be effective in that those focused directly on symptoms show results similar to those that reduced symptoms indirectly by focusing on risk factors.

\section{Acknowledgments}

Ms Philippa Cannan is thanked for her assistance with coding and entering the data.

The Faculty of Business, University of Tasmania provided funding for this project. K Sanderson was supported by a public health (Australia) fellowship (\#290538) from the National Health and Medical Research Council.

\section{References}

1. Blonk R, Brenninkmeijer V, Lagerveld S, Houtman I. Return to work: a comparison of two cognitive behavioural interventions in cases of work-related psychological complaints amongst the self-employed. Work Stress. 2006;20(2):129-44.

2. Atlantis E, Chow C, Kirby A, Singh M. An effective exercisebased intervention for improving mental health and quality of life measures: a randomised controlled trial. Prev Med. 2004;39(2):424-34.

3. Bond F, Bunce D. Mediators of change in emotion-focused and problem-focused worksite stress management interventions. J Occup Health Psychol. 2000;5(1):156-63.

4. Grime P. Computerised cognitive behavioural therapy at work: a randomised controlled trial in employees with recent stressrelated absenteeism. Occup Med. 2006;54(5):353-9.

5. Kawakami N, Araki S, Kawashima M, Masumoto T, Hayashi T. Effect of work-related stress reductions on depressive symptoms among Japanese blue-collar workers. Scand J Work Environ Health. 1997;23(1):54-9.

6. McCraty R, Atkinson M, Tomasino B. Impact of a workplace stress reduction program on blood pressure and emotional health in hypertensive employees. J Altern Complement Med. 2003;9(3):355-69.

7. Mino Y, Barbazono A, Toshihide T, Nobufumi Y. Can stress management in the workplace prevent depression?: a randomised controlled trial. Psychother Psychosom. 
2006;75(3):177-82.

8. Peters KK, Carlson JG. Worksite stress management with high-risk maintenance workers: a controlled study. Int J Stress Manage. 2004;6(1):21-44.

9. Sheppard W, Staggers F, John L. The effects of a stress management program in a high security government agency. Anxiety Stress Coping. 1997;10(4):341-50.

10. Brouwers E, Tiemens B, Terluin B, Verhaak P. Effectiveness of an intervention to reduce sickness absence in patients with emotional distress or minor mental disorders: a randomised controlled effectiveness trial. Gen Hosp Psychiatry. 2006;28(3):223-9.

11. Butterworth S, Linden A, McClay W, Leo M. Effect of motivational interviewing-based health coaching on employees' physical and mental health status. J Occup Health Psychol. 2006;11(4):358-65.

12. Feuerstein M, Nicholas R, Huang G, Dimberg L, Ali D, Rogers H. Job stress management and ergonomic intervention for work-related upper extremity symptoms. Appl Ergon. 2004;35(6):565-74.

13. Gardner B, Rose J, Mason O, Tyler P, Cushway D. Cognitive therapy and behavioural coping in the management of work-related stress: an intervention study. Work Stress. 2005; 19(2):137-52.

14. Godard C, Chevalier A, Lecrubier Y, Lahon G. APRAND programme: an intervention to prevent relapses of anxiety and depressive disorders: first results of a medical health promotion intervention in a population of employees. Eur Psychiat. 2006;21(7):451-9.

15. Kawakami N, Haratani T, Iwata N, Imanaka Y, Murata K, Araki S. Effects of mailed advice on stress reduction among employees in Japan: a randomised controlled trial. Ind Health. 1999;37(2):237-42.

16. Kitchener B, Jorm A. Mental health first aid training in a workplace setting: a randomised controlled trial. BMC Psychiatry. 2004:4:23.

17. Mutrie N, Carney C, Blamey A, Crawford F, Aitchison T, Whitelaw A. "Walk in to Work Out": a randomised controlled trial of a self help intervention to promote active commuting. J Epidemiol Community Health. 2002;56(6):407-12.

18. McClanahan T, Antonuccio D. Depression. In: Thomas J, Hersen M, editors. Psychopathology in the workplace: recognition and adaptation. New York (NY): Brunner-Routledge; 2004. p 133-46.

19. Kupfer D, Frank E, Perel J. The advantage of early treatment intervention in recurrent depression. Arch Gen Psychiatry. 1989;46(9):771-5.

20. Wang PS, Simon GE, Avorn J, Azocar F, Ludman EJ, McCulloch $\mathrm{J}$, et al. Telephone screening, outreach, and care management for depressed workers and impact on clinical and work productivity outcomes: a randomized controlled trial. JAMA. 2007;298(12):1401-11.

21. Morrow L, Verins I, Willis E, editors. Mental health and work: issues and perspectives. Adelaide (Australia): Auseinet (The Australian Network for Promotion, Prevention and Early Intervention for Mental Health); 2002.

22. Sanderson K, Andrews G. Common mental disorders in the workforce: recent findings from descriptive and social epidemiology. Can J Psychiatry. 2006;51(2):63-75.

23. Haslam C, Atkinson S, Brown S, Haslam R. Anxiety and depression in the workplace: effects on the individual and organisation. J Affect Dis. 2005;88(2):209-15.

24. McDaid D, Curran C, Knapp M. Promoting mental well-being in the workplace: a European policy perspective. Int Rev
Psychiatry. 2005;17(5):365-73.

25. Dewa C, Lesage A, Goering P, Craveen M. Nature and prevalence of mental illness in the workplace. Healthcare Pap. 2004;5(2):12-25.

26. Bender A, Kennedy S. Mental health and mental illness in the workplace: diagnostic and treatment issues. Healthcare Pap. 2004;5(2):54-67.

27. Cattan M. Introduction. In: Cattan M, Tilford S, editors. Mental health promotion: a lifespan approach. Berkshire (UK): McGraw Hill; 2006. p 1-7.

28. MacDonald G. What is mental health? In: Cattan M, Tilford S, editors. Mental health promotion: a lifespan approach. Berkshire (UK): McGraw Hill; 2002. p 8-32.

29. Mrazek P, Haggerty R. Reducing risks of mental disorder: frontiers for preventive intervention research. Washington (DC): National Academy Press; 1994.

30. Sullivan S. Promoting health and productivity for depressed patients in the workplace. J Manage Care Pharm. 2005;11(3):12-5.

31. Giga SI, Cooper CL, Faragher B. The development of a framework for a comprehensive approach to stress management interventions at work. Int J Stress Manage. 2003;10(4):280-96.

32. Richardson KM, Rothstein HR. Effects of occupational stress management intervention programs: a meta-analysis. J Occup Health Psychol. 2008;13(1):69-93.

33. van der Klink JJ, Blonk RW, Schene AH, van Dijk FJ. The benefits of interventions for work-related stress. Am J Public Health. 2001;91(2):270-6.

34. Avey S. Challenges facing employers in the treatment of depression. J Managed Care Pharm. 2005;11(3):3-4.

35. Kivimäki M, Virtanen M, Elovainio M, Kouvonen A, Väänänen A, Vahtera J. Work stress in the etiology of coronary heart disease - a meta-analysis. Scand J Work Environ Health 2006;32(6, special issue):431-42.

36. Blaine B, Rodman J, Newman J. Weight loss treatment and psychological well-being: a review and meta-analysis. J Health Psychol. 2007;12(1):66-82.

37. Tetlie T, Eik-Nes N, Palmstierna T, Callahan P, Nottestad JA. The effect of exercise of psychosocial and physical health outcomes: preliminary results from a Norwegian forensic hospital. J Psychosoc Nurs Ment Health Serv. 2008;46(7):38-43.

38. Kilbourne A, Post E, Nossek A, Drill L, Cooley S, Bauer M. Improving medical and psychiatric outcomes among individuals with bipolar disorder: a randomised controlled trial. Psychiatr Serv. 2008;59(7):760-8.

39. Goetzel RZ, Ozminkowski RJ, Bowen J, Tabrizi MJ. Employer integration of health promotion and health protection programs. Int J Work Health Manage. 2008;1(2):109-22.

40. Schulte P, Goldenhar L, Connally L. Intervention research: science, skills, and strategies. Am J Ind Med. 1996;29(4):258-88.

41. Lang T, Nicaud V, Slama K, Hirsch A, Imbernon E, Goldberg M. Smoking cessation at the workplace: results of a randomised controlled intervention study. J Epidemiol Community Health. 2000;54(5):349-54.

42. Bray M, Theodore L, Patwa S, Margiano S, Alric J, Peck H. Written emotional expression as an intervention for asthma. J Appl Sch Psychol. 2003;22(1):141-65.

43. Richmond R, Kehoe L, Heather N, Wodak A. Evaluation of a workplace brief intervention for excessive alcohol consumption: the Workplace Project. Prev Med. 2000;30(1):51-63.

44. Sjögren T, Nissinen K, Järvenpää S, Ojanen M, Vanharanta $\mathrm{H}$, Mälkiä E. Effects of a physical exercise intervention on subjective physical well-being, psychosocial functioning and general well-being among office workers: a cluster ran- 
domised-controlled cross-over design. Scand J Med Sci Sports 2006;16:381-90.

45. Ferrie J, Head J, Shipley M, Vahtera J, Marmot M, Kivimäki M. Injustice at work and the incidence of psychiatric morbidity: the Whitehall II study. Occup Environ Med. 2006;63(7):443-50.

46. Kompier M. Job design and wellbeing. In: Schabracq MJ, Winnubst JAM, Cooper CL, editors. The handbook of work and health psychology. 2nd ed. Chichester (UK): Wiley \& Sons Ltd; 2003. p 429-54.

47. Gill S, Butterworth P, Rodgers B, Mackinnon A. Validity of the mental health component scale of the 12-item short-form health survey (MCS-12) as a measure of common mental disorders in the general population. Psychiatry Res. 2007;152(1):63-71.

48. Hunter JE, Schmidt FL. Methods of meta-analysis: correcting error and bias in research findings. Newbury Park (CA): Sage Publications; 1990.

49. Lipsey M, Wilson D. Practical meta-analysis. Thousand Oaks (CA): Sage Publications; 2001.

50. Higgins J, Green S, editors. Cochrane handbook for systematic reviews of interventions 4.2.6 [updated September 2006]. Chichester (UK): John Wiley \& Sons, Ltd; 2006.

51. The Cochrane Collaboration. The Cochrane manual. 2nd ed. Oxford (UK): The Cochrane Collaboration; 2008.

52. Terrin N, Schmid CH, Lau J. In an empirical evaluation of the funnel plot, researchers could not visually identify publication bias. J Clin Epidemiol. 2005;58:894-901.

53. McCraty R, Atkinson M, Lipsenthal L, Arguelles L. Impact of the power to change performance program on stress and health risks in correctional officers. Boulder Creek (CA): HeartMath Research Center, Institute of HeartMath; 2003.

54. Munz DC, Kohler JM, Greenberg CI. Effectiveness of a comprehensive worksite stress management program: combining organizational and individual interventions. Int J Stress Manage. 2001;8(1):49-62.

55. Guppy A, Marsden J. Assisting employees with drinking problems: change in mental health, job perceptions and work performance. Work Stress. 1997;11:341-50.

56. Lavoie-Tremblay M, Bourbonnais R, Viens C, Vezina M, Durand $\mathrm{P}$, Rochette L. Improving the psychosocial work environment. J Adv Nurs. 2005;49(6):655-64.

57. Gloaguen V, Cottraux J, Cucherat M, Blackburn I-M. A meta-analysis of the effects of cognitive therapy in depressed patients. J Affect Dis. 1998;49(1):59-72.

58. Jané-Llopis E, Hosman C, Jenkins R, Anderson P. Predictors of efficacy in depression prevention programmes: meta-analysis. Br J Psychiatry. 2003;183(5):384-97.

59. Rose G. The strategy of preventive medicine. Oxford (UK): Oxford University Press; 1993.

60. Goetzel RZ, Ozminkowski RJ. The health and cost benefits of work site health-promotion programs. Annu Rev Public Health. 2008;29:303-23.

61. Murphy L. Workplace interventions for stress reduction and prevention. Chichester (UK): John Wiley \& Sons Inc; 1988.
62. Burke R. Organisational-level interventions to reduce occupational stressors. Work Stress. 1993;7(1):77-87.

63. DeFrank R, Cooper C. Worksite stress management interventions: their effectiveness and conceptualisations. J Manage Psychol. 1987;2(1):4-9.

64. Briner R, Reynolds S. The costs, benefits, and limitations of organisational level stress interventions. J Organ Behav. 1999;20(5):647-65.

65. Semmer NK. Job stress interventions and the organisation of work. Scand J Work Environ Health. 2006;32(6, special issue):515-27.

66. Giga SI, Cooper CL, Faragher B. The development of a framework for a comprehensive approach to stress management interventions at work. Int J Stress Manage. 2003;10(4):280-96.

67. Murta S, Sanderson K, Oldenburg B. Process evaluation in occupational stress management programs: a systematic review. Am J Health Promot. 2007;21(4):248-54.

68. Griffiths A. Organisational interventions: facing the limits of the natural science paradigm. Scand J Work Environ Health. 1999;25(6, special issue):589-96.

69. Kristensen T. Workplace intervention studies. Occup Med. 2000;15(1):239-305.

70. Petterson I, Donnersvard H, M L, Toomingas A. Evaluation of an intervention programme based on empowerment for Eldercare nursing staff. Work Stress. 2006;20(4):353-369.

71. Lovibond S, Lovibond P. Manual for depression, anxiety and stress scale. 2nd ed. Sydney (Australia): Psychology Foundation; 1995.

72. Beck A, Ward C, Mendelson M, Mock J, Erbaugh J. An inventory for measuring depression. Arch Gen Psychiatry. 1961;4:561-71.

73. Zigmond A, Snaith R. The hospital anxiety and depression scale. Acta Psychiatr Scand. 1983;67(6):361-70.

74. Zung W. A self-rating depression scale. Arch Gen Psychiatry. 1965;12:63-70.

75. Derogatis L, Spencer P. The brief symptom inventory. Baltimore (MD): LR Derogatis; 1982.

76. Radloff L. The CES-D scale: a self report depression scale for research in the general population. Appl Psychol Meas. 1977;1(3):385-401.

77. Speilberger C, Gorschurch R, Lushene R, editors. STAI Manual for the State-Trait Anxiety Inventory. Palo Alto (CA): Consulting Psychologists Press; 1990.

78. Ware J, Kosinski M, Keller S. A 12-Item Short Form Health Survey (SF-12): construction of scales and preliminary tests of reliability and validity. Med Care. 1996;34(3):220-33.

79. Ware J, Snow K, Kosinski M. SF-36 Health Survey: manual and interpretation guide. Lincoln (RI): Quality Metric Incorporated; 1993.

80. Goldberg D. General Heath Questionnaire. Windsor (United Kingdom): NFER-Nelsom; 1992.

Received for publication: 4 April 2008

\section{Appendix 1: Search strategy}

Search parameters were created to identify studies that met the following criteria:

1. Published in the past 10 years (January 1997-January 2007)
2. Promoted the mental health of employees:

- Targeting a known risk factor or a protective factor for depression or anxiety.

- See key words below for "risk or protective factors" 
OR

- Targeting depression or anxiety or emotional or psychological distress directly

- See key words below for "outcomes"

3. Included a valid outcome measure of depression and anxiety:

- Centre for Epidemiological Studies Depression scale (CESD)

- Depression, anxiety and stress scales (DASS)

- Beck depression and anxiety inventories (BDI and BAI)

- Patient Health Questionnaire (PHQ)

- Hopkins Symptom Checklist (HSC)

- DSM-IV Structured Clinical Interview Diagnosis (SCID) for depression and anxiety

- General Health Questionnaire (GHQ)

- Composite International Diagnostic Interview (CIDI)

- SF - 36/ SF-12 (MHI/ MCS)

4. Evaluated an intervention program.

- See key words below for "intervention"

5. Delivered via a workplace and involved working adults as the population of interest.

- See key words below for "workplace"

6. Used methodology that included quantitative longitudinal measurement such as a quasi-experimental or experimental design

- See key words below for "design"

7. Major database search engines used:
a. MEDLINE
b. Meditext
c. PsycINFO
d. CINAHL
e. Proquest
f. Business Source Premier
g. Web of Science
h. Medge
i. Ingenta
j. Wiley Interscience Journals
k. PsycArticles
1. PubMed

8. Journals searched by hand:

Anxiety, Stress and Coping

Applied Ergonomics

BMC Psychiatry

European Psychiatry

General Hospital Psychiatry

Industrial Health

International Journal of Stress Management

Journal of Alternative and Complementary Medicine

Journal of Epidemiology and Community Health

Journal of Occupational Health Psychology

Journal of Occupational \& Environmental Medicine

Journal of Occupational and Organizational Psychology

Journal of Organisational Behaviour

Occupational Medicine

Preventive Medicine

Psychotherapy and Psychosomatics

Scandinavian Journal of Work, Environment \& Health

Work \& Stress

\begin{tabular}{|c|c|c|c|c|}
\hline $\begin{array}{l}\text { Keywords for risk or pro- AND } \\
\text { tective factors (OR) }\end{array}$ & $\begin{array}{l}\text { Keywords for out- AND } \\
\text { comes (OR) }\end{array}$ & $\begin{array}{l}\text { Keywords for workplace AND } \\
\text { (OR) }\end{array}$ & $\begin{array}{l}\text { Keywords for inter- } \\
\text { vention (OR) }\end{array}$ & $\begin{array}{l}\text { Keywords for design } \\
\text { (OR) }\end{array}$ \\
\hline $\begin{array}{l}\text { Health } \\
\text { Disease } \\
\text { Stress } \\
\text { Cop* (Coping/Cope) } \\
\text { Smoking } \\
\text { Alcohol } \\
\text { Drugs } \\
\text { Weight } \\
\text { Diet } \\
\text { Activity } \\
\text { Exercise } \\
\text { Support } \\
\text { Skills } \\
\text { Health Promotion } \\
\text { Self Esteem } \\
\text { Resilience } \\
\text { Env* } \\
\text { Job Quality } \\
\text { Phys* } \\
\text { Stigma } \\
\text { Early intervention }\end{array}$ & $\begin{array}{l}\text { Depress* } \\
\text { Anxi }^{*} \\
\text { Psych}^{*} \\
\text { Health } \\
\text { Symptom* } \\
\text { Well }^{*} \\
\text { Psych }^{*} \\
\text { Emotion }^{*} \\
\text { Distress } \\
\text { (specific mea- }^{*} \\
\text { sures listed) }\end{array}$ & $\begin{array}{l}\text { Organi*ation* } \\
\text { Employ* } \\
\text { Business* } \\
\text { Work* } \\
\text { Job } \\
\text { Labor/Labour } \\
\text { Corporat* } \\
\text { Occupation* } \\
\text { Manage* }^{*}\end{array}$ & $\begin{array}{l}\text { Used Cochrane } \\
\text { search terms } \\
+ \\
\text { Effect } \\
\text { Control } \\
\text { Eval }^{*} \\
\text { Program } \\
\text { Occup } \\
\text { Prevent }^{\star} \\
\text { Protect }^{\star}\end{array}$ & $\begin{array}{l}\text { Used Cochrane search } \\
\text { terms } \\
\text { Experimental } \\
\text { Quasi } \\
\text { Randomised } \\
\text { Controlled Trial (RCT) } \\
\text { Controlled Clinical Trial } \\
\text { Random* Trial } \\
\text { Groups } \\
\text { Longitudinal } \\
\text { Pre } \\
\text { Post }\end{array}$ \\
\hline
\end{tabular}

